\title{
La Medicina en la India Antigua
}

\author{
Juan Miguel de Mora \\ Universidad Nacional Autónoma de México
}

\begin{abstract}
MORA, J. M. La medicina en la India Antigua. Classica, Belo Horizonte, 3:80-92, 1990 .
\end{abstract}

RESUMO: A medicina na India antiga conheceu notável desenvolvimento, o que se pode comprovar pelo estudo dos tratados sobre temas médicos legados à posteridade. O presente trabalho apresenta uma síntese das principais idéias abordadas e desenvolvidas no corpus medicinal indiano.

En el tercer milenio antes de nuestra era, existíam en la India tales instalaciones balnearias que han hecho pensar si no estarian relacionadas con algún tipo de hidroterapia o con un concepto medicinal de la higiene.

En Mohenjo-Daro (Sindh) y en Harappa (Penjab) en la llamada civilización del Indo, cuya antigüedad de por lo menos tres mil años antes de nuestra era está fuera de duda, existían grandes trabajos de higiene urbana y particular: en las casas modestas, habia una habitación con embaldosado impermeable con pendiente hacia una canalización de desagüe; en las casas más grandes, verdaderos cuartos de baño. Asímismo, quedan los vestigios de un edificio destinado exclusivamente a baños, con un salón de 55 por 33 metros, además de una piscina de 13 metros por 7 y de una profundidad de 2 metros y medio y amplias dependencias que evidentemente se dedicaban también a usos balnearios. Lo excepcional es que todo esto desembocaba en un sistema de alcantarillas con ramificaciones en todas las calles y con fosas espaciadas para evitar el azolvamiento. Ahora bien, este tipo de trabajos de urbanización con drenaje no existión en ninguna otra parte en la antigüedad y cabe 
señalar que tres mil años después, la ciudad de Roma, capital dominadora de todo el mundo civilizado de entonces, no tuvo jamás nada semejante ni parecido.

La escritura de Mohenjo-Daro no ha sido descifrada y, naturalmente, no es posible saber si alguno de esos baños tenía carácter profilático o terapéutico como parte de un concepto medicinal. Sí es posible señalar, sin embargo, que en la medicina hindú posterior la hidroterapia es parte de los tratamientos así como que hay un concepto de la profilaxis y de la higiene.

Por otra parte, cuando llegaron los indoarios, lo que se supone ocurrió en el segundo milenio antes de nuestra era, traían, en el texto védico, ideas que posteriormente formaron parte del Ayurveda, la ciencia de la longevidad o antigua medicina de la India.

En un magnífico y detallado estudio filológico y lingüístico, Jean Filliozat (1975: 67 ss.) demostró que los himnos más antiguos del $R g V e d a$ no pueden ser posteriores a por lo menos 1550 antes de n. e. y también que el Atharva Veda, donde se encuentra lo principal de la antigua medicina de la India, es del siglo XV antes de nuestra era, hacia 1400.

Los cuatro vedasamhitas ( $R g$ Veda, Sama Veda, Yajur Veda y Atharva Veda), "colecciones" o "recopilaciones" del saber contienen una copiosísima nomenclatura anatómica y de secreciones y partes del cuerpo humano, en cantidad superior a trescientos vocablos, de los que aquí citaremos algunos:

Amsa, hombro; amhubhedi, vulva; anga, miembro; anguri, dedo; anghri, pie; pada, pie; antarodara, interior del vientre; alga, ingle; anda, testículo; ana, boca; anata, región del cuello; udara, abdomen; upapaksa, flanco, costado; upastha, órganos genitales femeninos; uras, pecho; usniha, protuberancias del cráneo; uru, muslo; kakatika, nuca; kaksa, axila; kantha, garganta; kaninaka, pupila; kapala, cráneo; kaprth, pene; kara, mano; karasna, antebrazo; karna, oreja; ktkasa, vértebra;kuksi, pelvis; garbha, embrión; gavinika, uréter; guda, recto; gulpha, tobillo; caksas, ojo; carman, piel; jangha, pierna; jatru, clavícula; jambila, estómago; jambha, mandíbula; jihva, lengua; tanu, cuerpo; nandathu, órgano sexual; nas, nariz; parus, articulación; parsva, pared toráxica; puritat, pericardio; prstha, espalda; barsva, encía; majjan, médula; mastiska, cerebro; 
muska, testículos; mutra, orina; murdhan, cabeza; mehana, penis como órgano urinario; yakan, hígado; yoni, matriz, vagina; vaksas, seno; vantsthu, colon; vasti, vejiga; vrkka, riñon; srotra, oído interno; samdhi, articulación; sthulaguda, intestino grueso; hardi, corazón; hira, vaso sanguíneo, etcétera.

En el Atharva Veda se identifican y clasifican las fiebres intermitentes, distinguiendo las cotidianas de las tercianas, las cuartanas, la contínua, la otoñal y la estival, así como la fiebre de la época de lluvias y otras más.

Los nombres de las enfermedades más numerosas se refieren a los síntomas considerados en sí mismos, como por ejemplo kasa, la tos; sirsakti, el dolor de cabeza; sula, dolor lancinante, y otros. La patología védica conocía también, como lo afirman Renou y Filliozat (1953:141), las heridas, los venenos y las lombrices intestinales.

Sin embargo, en los textos védicos se habla todavía en muchos casos en términos de magia, especialmente en lo que hace a la terapéutica, aunque es necesario subrayar que no toda era de ese tipo, pues se usaban ya pomadas, aplicaciones y otros medios de cura. Al respecto, Filliozat señala que es posible que el cateterismo vesical haya sido practicado.

Es muy importante precisar que está probada la existencia de médicos en la época védica, médicos que nada tenían que ver con los sacerdotes y los autores de himnos védicos, por lo cual estes últimos no les apreciaban. El Taittiriya Samhita, una de las tres grandes series de fórmulas de exégesis ritual que forman el Yajur Veda Negro, texto hecho por los brahmanes en parte para su beneficio, atestigua un gran desprecio por los médicos, sin duda porque ellos curaban de maneras diferentes a la recitación de himnos e invocaciones a los dioses.

En esta época que, recordamos lo dicho antes, no puede situarse después del siglo XV antes de nuestra era, existía una fisiologia védica primitiva - e imaginaria que concebia al viento como una fuerza a la vez orgánica y cósmica y que distinguía una multiplicidad de vientos orgánicos. La palabra prana significa en general soplo, aliento, y tiene gran trascendencia en la teoría fisiológica. Se divide la actividad respiratoria en inspiración y expiración y, a 
estos efectos, prana puede significar el proceso completo de la respiración o solamente inspiración, según el contexto. De acuerdo con la medicina hindú, el viento es el alma del mundo y del cuerpo y se le da la importancia que también tiene en el tratado hipocrático De los vientos, en el cual aparece la innegable influencia de las ideas hindúes.

Los tratados clásicos de la medicina hindú son tres: el Bhela Samhita, que ha llegado a nuestros días en un solo manuscrito que está incompleto, y el Caraka Samhita y Susruta Samhita, que no han llegado a la época actual en su versión original sino en revisiones y copias de autores posteriores. Pero, como lo subraya el mismo Filliozat (1975:1), "ninguno de los tres representa un primer ensayo de exposición de la ciencia médica, sino que, por el contrario, cada uno de ellos supone una misma tradición ya constituída que ellos no han contribuido a fundar y que se limitan a recoger y enseñar".

Queda claro, pues, que la medicina hindú, el Ayurveda, es muy anterior a estos tres tratados, por lo mismo que la occidental es muy anterior a los textos que se estudian hoy en las facultades respectivas o que se estudiaron en siglos pasados.

El Bhela Samhita, atribuido a Bhelacarya, está considerado, por su redacción, más antiguo que los otros dos. El Susruta Samhïta puede considerarse como una obra de siglos anteriores a nuestra era que ha llegado a nosotros en una forma fijada en el curso de los primeros siglos de ésta, según Filliozat. Y el Caraka Samhita corresponde al siglo II anterior a nuestra era.

La palabra astanga, cuya traducción literal sería "ocho artículas" pero que se suele traducir por "la ciencia de los ocho artículos", tiene el significado general de "medicina" debido a que el Ayurveda consta, teóricamente, de ocho partes, contenidas en mil capítulos y 100.000 slokas (dísticos). Sin embargo, los tratados de medicina que conservamos no siguen esa clasificación al pie de la letra, aunque si tratan de lo comprendido en las ocho partes, que son:

Salya: cirugía general, incluyendo extracción de cuerpos extraños, de fetos muertos, etcétera, además de la cauterización. Veremos los instrumentos quirúrgicos al tratar del Susruta Samhita. 
Salakya que es, de hecho, una oftalmología y una otorrinolaringología .

Kayacikitsa: medicina general, de todo el cuerpo.

Bhatavtdya: literalmente "ciencia de los demonios" (tomando esta última palabra en un sentido muy amplio, de "malos espíritus" y no en la concepción católica del diablo); trata de los poseídos, probablemente de la epilepsia y los ataques, considerados como una posesión de malos espíritus.

Kaumarabhrtya: lo que hoy llamamos puericultura.

Agadatantra: tratado de los antídotos contra los venenos que es, por lo tanto, una toxicología.

Rasayana: tratado de los fortificantes y el rejuvenecimiento.

Vajikarana: tratado de los afrodisíacos y cuestiones de la virilidad.

Antes de entrar a la exposición de los dos samhitas principales, el Susruta y el Caraka, cabe precisar que ambos expresan un sistema racional en el que la magía y la mística no aparecen, y que únicamente se refieren a "malos espíritus" en dos casos: la posesión o las enfermedades de los niños. "Por lo general - precisa Filiozat - explican los estados de salud y de enfermedad por el juego de los elementos del organismo, el régimen alimenticio y las influencias del tiempo en cada estación".

El Susruta Samhita se divide en seis partes, la primera de las cuales es el sutrasthana, que habla de los orígenes míticos del Ayurveda, de las condiciones para estudiarlo, los deberes del médico, la influencia del tiempo sobre la patología y otras muchas cuestiones médicas en un desorden ajeno a toda clasificación, lo que hace pensar en revisiones o interpolaciones. Pero en su capítulo 15, describe la perforación de las orejas, la reparación de lóbulos desgarrados y la rinoplastía (en sánscrito nasikayah sandhanavidhi). En el capítulo 24, explica que unas enfermedades son curables con cirurgía y otras con ungüentos y otros remedios. Esta primera parte se ocupa de la cirugía en general y describe diversas operaciones así como instrumentos quirúrgicos. 
En materia de cirugía (sastrakarma), el Susruta describe ocho tipos: chedya, excisión; lekhya, escarificación; vedhya, punción; esya, exploración; aharya, extracción; visravya, evacuación y sivya, sutura.

Respecto de los instrumentos quirúrgicos, describe ciento uno romos y veinte filosos, hablando de, por ejemplo, según la ennumeración de Subbrayappa $(1970: 56)$, fórceps, tenazas, escalpelos, catéteres, bougies, trocares, jeringas, espéculos, agujas, sierras, tijeras, lancetas, ganchos y estiletes.

Al mencionar los instrumentos, se dan detalles de cómo hacerlos de metal, de sus dimensiones, etcétera.

Entre los adelantos a los que se había llegado en época tan lejana, cabe señalar la oftalmología, que incluía extracción de cataratas (en un tiempo en que ni en Grecia ni en Egipto se conocía el procedimiento) así como la forma quirúrgica de tratar afecciones del párpado. También se operaba el cráneo, la fístula anal, el abdomen, etcétera, y se hacía la ligazión de los vasos sanguíneos, con gran avance en proporción a su tiempo. Se ponía mucha atención en la enseñanza de la medicina, practicando con frutas y con animales, se daba gran importancia a los períodos pre y pos operatorio y se usaba mucho el alcohol, como veremos más adelante.

El material para suturas externas era generalmente de lino, cáñamo o fibras vegetales, pero para heridas internas, incluyendo las de vientre, que requieren un material absorbible, utilizaban el siguiente procedimiento: uno de los médicos juntaba los labios de la herida y otro hacía que los mordiera una hormiga (grande, pero normal) a la que se cortaba la cabeza en el momento de afianzar sus mandíbulas. De esta manera, cada cabeza de hormiga se convertía en una grapa de material absorbible por el organismo.

Nidanasthana: En esta segunda parte del Susruta Samhita, se trata de lo que hoy llamamos etiología y patogenia: las causas de las enfermedades como hemorroides (arsas), cálculos vesicales (asmari), fítulas anales (bhagamdara), dermatosis (kustha), enfermedades urinarias (prameha), la hidropesía (udara), distocias (mudhagarbha), flemones viscerales (vidradhi), erisipelas y males de los canales y de los senos (visarpanadhisthanaroga), adenopatías 
nodulosas o confluentes, excrecencias y bocios (granthi-apaciarbuda-galaganda), hinchazones, afecciones genitales y elefantiasis (vrddhiupamsaslipada), males menores diversos (ksudraroga), molestias debidas al suka (insecto vesicante utilizado como afrodisíaco), fracturas y luxaciones (bhagna) y males de la boca (mukharoga). Como es evidente, esta sección es de una gran importancia, como ya lo han reconocido Renou y Filliozat $(1953: 145)$.

Sarirasthana: sección teórica sobre la estructura, el desarrollo y las funciones de los órganos, naturalmente no al nivel de los conocimientos modernos y frecuentemente arbitraria, aunque atestigua "una observación bastante profunda y de una concepción coherente".

Cikitsasthana: Esta parte comprende la terapéutica en 40 capítulos. Comienza con el tratamiento de dos tipos de lesiones (las llagas espontáneas por enfermedad orgánica y las heridas de origen traumático) y sigue con los tratamientos de las enfermedades estudiadas en el Nidanasthana. Cabe destacar que el capítulo 24 está dedicado a la higiene, cuando faltaban milenios para que en otras regiones del mundo se pensara siquiera en ella en relación con la medicina. El final de esta parte se dedica a preparaciones farmacéuticas.

Kalpasthana: está dedicado en sus ocho capítulos a la toxicología, venenos de animales y medidas para impedir que el rey sea envenenado. Es decir que abarca el agadatantra, una de las divisiones clásicas del Ayurveda.

Uttaratantra: comprende diversos aspectos de medicina general, fortificantes y rejuvenecimiento, afrodisíacos y el más notable tratado de oftalmología que haya llegado hasta nosostros procedente de cualquier civilización antigua. Tratando también de garganta, nariz y oídos, cubre la parte del Ayurveda que se llama salakya. Versa asímismo sobre ginecologia y enfermedades infantiles y los últimos capítulos se refieren a cuestiones de higiene alimenticia.

El sánscrito en que está escrito el Susruta Samhita es arcaizante y prueba que procede de algunos siglos antes de la era cristiana aunque, como ya se dijo, no se puede considerar sino como un tratado que sigue a otros muy anteriores. 
El Caraka Samhita tiene una característica muy interessante: dedica una buena parte a ensalzar el alcohol como medicamento. Dicho de otro modo, desde antes de la era cristiana, hace de dos mil años, los médicos hindúes sabían que el alcohol es bueno como medicamento $\mathrm{y}$ de valor profiláctico puesto que se utilizaba en heridas y llagas, para evitar que se infectaran. Había un ritual llamado sautramani y también uno llamado carakasautramani. El primero consistía en el ofrecimiento de la bebida alcohólica llamada sura a los Asvines, a Sarasvati y a Indra y el segundo era una variante con alusión médica. El indólogo alemán Hillebrandt (1853-1927) relacionó el carakasautramani con el Caraka Samhita, en lo cual no están de acuerdo otros estudiosos.

El hecho es que hubo un médico hindú de la antigüedad llamado Caraka que atendió al emperador Kaniska del norte de la India a principios de la era cristiana, según se cree, y que fue el compilador del Caraka Samhita. Pero diversas investigaciones acusan la posible existencia de otros médicos con el mismo nombre.

Sucede, por otra parte, que caraka procede de la raíz car, que en sí y en sus derivados implica moverse, andar, circular, etcétera . Cara significa móvil, que anda, que circula, errante.

Filliozat apunta que en el ya mencionado Taittiriya Samhita se llama a los Asvines impuros como "médicos ambulantes entre los hombres" y para llamarles errantes o ambulantes se emplea el vocablo cara.

El texto que cita Filliozat demuestra que existían en la más lejana antiguiedad hindú los médicos ambulantes. Y como la partícula $k a$ significa "quien" o "el desconocido" (además de nombre de Prajapati, de Brahma y de Daksa) o “¿quién?" como pronombre interrogativo, bien pudo ser Caraka el nombre general dado a los médicos ambulantes en una cierta época y región. A partir de ahí, hubo uno o varios Caraka que fueron famosos por sus aciertos y de ahí el Caraka al que atribuye la leyenda haber sido médico de Kaniska y otros carakas que se encuentran en los textos antiguos. Ése es nuestro personal punto de vista, que no hemos encontrado en los autores consultados. 
Caraka Samhita significa "recopilación de Caraka" y tiene muy aproximadamente la misma extensión del Susruta Samhita al que se asemeja por el estilo general, el tipo de sánscrito que en él se emplea y hasta los versos y los metros. Hay diferencias como el hecho de que el Caraka no se ocupa tanto de la cirugía ni le da tanta importancia como el Susruta, pero hay en ambos algunos versos comunes. Si fueron producto de alguna interpolación de uno en otro o si ambos los tomaron de un tratado más antiguo que sirvión a ambos de fuente original (¿Agnivesa?), es cosa que no puede dilucidarse con los elementos de juicio de que disponemos hasta ahora.

El Caraka se divide en ocho capítulos principales: el Sutrasthana, que trata de los remedios, recetas medicinales, higiene, terapéutica y otras materias afines; el Nidanasthana, que se ocupa de las causas de ocho tipos de enfermedades, las fiebres, los males de la sangre y de la bilis, los tumores, las afecciones urinarias, la dermatosis, la consunción, la locura y la epilepsia; el Vimanasthana, hablando de la digestión, las epidemias, los jugos y otros temas heterogéneos; el Sarirasthana, que trata del hombre, la embriología, la anatomia y la obstetricia, además de contener una exposición filosófica acerca de las relaciones entre el cuerpo y el espíritu; el Indriyasthana, que contiene doce capítulos tratando de la observación del color del enfermo, de la voz, de su olfato y su gusto, de su tacto, alucinaciones o sucños y otros aspectos de los sentidos; el Cikitsasthana, sección de terapéutica en treinta capítulos, tratando en cada caso primeiro de la descripción de los síntomas y de las causas y después de los medios para la cura respectiva; el Kalpasthana, todo él sobre preparados de farmacia y el Siddhisthana que explica las lavativas, los lavados médios, inyecciones uretrales y otros recursos terapéuticos, con sus indicaciones y contraindicaciones, amén de muchas fórmulas para preparar líquidos medicinales inyectados.

No siendo este trabajo un tratado de medicina, nos limitamos a dar una breve reseña de tales tratados, sin entrar en detalles que requerirían los conocimientos de un médico. 
La doctrina del Ayurveda se apoya en tres de las darsanas ortodoxas o sistemas filosóficos de la India: el Samkhya, el Yoga y el Vaisesika, que no es éste el lugar para explicar. ${ }^{1}$

Conforme a esa doctrina, el mundo y el cuerpo humano están constituidos por los mismos elementos: la tierra, el fuego, el viento, el agua y el vacío.

Viento, fuego y agua son tres elementos activos que obran en todas las partes del cuerpo y que mantienen la ordenación necesaria. Como elemento activo en el organismo humano, el viento tiene los mismos nombres que se le dan como fenómeno atmosférico (Vayu, Vata y otros), y se considera que por el cuerpo humano circula en forma de corrientes de aire como en el espacio, es decir que se mantiene como aire, sin revestir formas diferentes como sucede, por ejemplo, con el fuego y el agua.

El Caraka Samhita y el Bhela explican que el viento en el cuerpo se divide en cinco pranas (soplos o alientos). El primero, prana por excelencia, se encuentra en la boca y sustenta al cuerpo haciendo circular el alimento y el aire. El udana, situado encima de las clavículas, produce la expiración y la palabra. El samana, en los órganos digestivos, muele las materias en la digestión y atiza el fuego que las cuece. El apana, en la base del cuerpo, expulsa las materias fecales y la orina $y$, en las mujeres, produce el parto. El último prana, el vyana, circula por todo el cuerpo, empujancio la sangre y los fluídos en general y produciendo todos los movimentos. El Susruta identifica el viento con el alma universal.

Pues bien, el tratado hipocrático De los vientos enseña la misma doctrina y expone las mismas ideas generales de los textos sánscritos de medicina de los que venimos hablando.

Jean Filliozat, quien antes de ser sanscritista estudió la carrera de medicina y se doctoró en ella, hace un análisis profundo de este hecho en la obra suya que hemos mencionado y expresa: "La comcordancia general de la doctrina del texto (hipocrático) con la del pneumatismo hindú es evidente. Las similitudes en el detalle de las representaciones patógenas no lo son menos".

1

Pueden verse diversos textos sobre las seis darsanas. Por ejemplo: Mora, 1968. Para la doctrina ayrvédica, ver Filliozat, 1975. 
Por otra parte es sorprendente la coincidencia de la teoría de los vientos y de las enfermedades que producen, doctrina clásica de la medicina hindú, con el texto del diálogo Timeo de Platón, el cual, por cierto, no corresponde a ningún texto griego de medicina que presente las cosas como él lo hace. Por otra parte, como la teoría de los vientos no corresponde a ninguna realidade anatómica, no puede derivarse que se haya llegado a las mismas conclusiones en Grecia que en la India. Y como los textos sánscritos son mucho más antiguos, no hay duda que fueron las ideas del Ayurveda las que inspiraron no sólo al texto hipocrático De los vientos, sino también al Timeo.

Para no ser prolijos y no abundar en lo que otros con autoridad en medicina ya han analizado y estudiado, veremos una parte del Susruta Samhita que describe el tétanos tal como lo entendía la antigua doctrina del Ayurveda, para después reproducir el texto de Platón sobre lo mismo. Dice el Susruta, en la traducción de Filliozat (1975:180-182) :

Cuando "la sangre llega a la corrupción y bloquea el camino del viento, éste, violentamente excitado por el bloqueo de su camino, puede perturbar de inmediato la sangre. La sangre, mezclada con el viento turbado por su predominio, se llama "sangre ventosa". E igual la bilis mezclada con la sangre alterada y la pituita alterada mezclada con la sangre enturbiada. Temiendo el contacto, sufriendo pinchazos, grietas, desecación, e insensibilidad se ponen los pies debido a la sangre ventosa. A consecuencia de la bilis y de la sangre sufren una inflamación violenta, están muy calientes, se ponen hinchados y rojos y muy lisos. Están pruriginosos, blancos $\mathrm{y}$ frios, inflamados e impotentes cuando la sangre es alterada por la pituita (42 a 45).

Pero cuando el viento irritado invade todos los conductos (vasos) entonces, de forma repentina, convulsiona vivamente $\mathrm{y}$ en todo momento el cuerpo $\mathrm{y}$, como lo convulsiona en todo tiempo, se llama tradicionalmente "convulsionador". Se llama "tensor" al que hace caer por intervalos, si el viento asociado a la pituita ocupa violentamente los vasos. El que hace mantenerse rigido como un bastón es grave, es el "tensor en bastón" (tétanos rígido). Cuando agarra muy fuertemente la mandíbula se dificulta la alimen- 
tación. El que curva como un arco toma su nombre de la rigidez en arco. Radica en los dedos, los tobillos, el abdomen, el corazón, el pecho y la garganta. Cuando el viento impetuoso convulsiona la expansión de los tendones se tienen los ojos fijos, la mandíbula rígida, el costado torcido, vomitando pituita. Cuando el hombre se dobla como un arco hacia dentro, entonces el viento poderoso provoca su "contracción hacia dentro" (emprosthotonos), y si está en las expansiones de los tendones de afuera (plantas de los piés, pantorrillas, etcétera), provoca la "contracción para fuera" (opisthotonos). Los expertos dicen incurable el que encorva el pecho, las caderas y los muslos. El viento asociado a la pituita y a la bilis $y$ hasta el viento solo puede producir el "convulsionador" (49 a 57).

Vejamos ahora una parte del texto de Timeo de Platón (1975) :

Cuando el pulmón, encargado de distribuir el aire al cuerpo no le presenta los conductos libres por estar obstruidos por los desagües, este aire, no yendo a ciertas partes y penetrando en cambio con exceso en otras, deja corromperse a las primeras que no se han refrigerado, y por otro lado entra violentamente en las venas, las retuerce con fuerza, disuelve el cuerpo, se encierra en la región interior ocupada por el diafragma y engendra mil dolorosas enfermedades acompañadas de sudores excesivos. A menudo, cuando la carne se encuentra dividida en el interior del cuerpo, se forma en ella aire que en la imposibilidad de escaparse produce los mismos dolores que el aire que se introdujera desde el exterior; dolores que llegan a su paroxismo cuando este aire, rodeando a las venas y a los nervios de estas partes e hinchando los músculos y los nervios con ellas relacionados, opera una tensión en sentido inverso. De esta tensión es de la que estas enfermedades han tomado el nombre de tétanos y opistotonos contra las que no es fácil encontrar remedio, y si se curan es casi siempre por las fiebres que producen. La pituita blanca es peligrosa si el aire de sus ampollas o burbujas queda detenido en el interior y benigna cuando se abre camino a través del cuerpo, pero entonces ensucia la piel cubriéndola de herpes y otras afecciones análogas engendradas por ella. Mezclada a la bilis negra y repartida entre las 
revoluciones divinas que se verifican en la cabeza, a las que lleva el desorden, es menos dañina si las invade durante el sueño, pero si es en la vigilia resulta casi invencible a los esfuerzos del arte.

Ciertamente en el Timeo se mencionam los pulmones y la bilis negra que en el fragmento reproducido del Susruta no aparecen, pero es idudable que ambos textos se basan en la misma teoría de los vientos y que en cuanto el tétanos tienen una concordancia casi total. No se trata de que el texto hindú haya sido copiado, pero sí de que las ideas del Ayurveda influyeron decisivamente en el escrito por Platón.

La doctrina del Ayurveda se dijó sistemáticamente entre los siglos VIII y VI antes de nuestra era. Timeo fue uno de los últimos textos de Platón, escrito en el segundo cuarto del siglo IV antes de nuestra era. En cuanto al tratado hipocrático De los vientos, pertenece a un tiempo cercano al de Platón y sin duda alguna es anterior a Alejandro. La simple concordancia entre las medicinas hindú y griega, demonstrada ampliamente por Jean Filliozat, es prueba suficiente de que existieron intercambios de ideas entre ambos países en épocas arteriores a la de Alejandro Magno.

Por otra parte, la medicina hindú se había extendido por diversos países. No sólo las fórmulas médicas y las plantas medicinales hindús circulaban en Grecia desde antes de Alejandro, sino que el Ayurveda se extendió por diversos pueblos de Asia a lo largo de diferentes épocas que no siempre es posible precisar. Las pruebas concluyentes de esa influencia de la medicina hindú son relativamente recientes, pero es imposible saber desde cuántos siglos antes existía esa influencia.

En Persia, la medicina hindú es conocida desde hace muchos siglos. El médico persa Ali ibn Rabbun at Tabari escribió en el año 850 de nuestra era un tratado que incluye muchos datos acerca de la medicina hindú. Se llama Firdaus ul hikmat.

En el Tibet circularon en la antigüedad tratados médicos hindúes traducidos al tibetano, incluídos en la gran colección Tanjur. Y la medicina veterinaria hindú, muy desarrolada especialmente en lo que hace a los caballos, las vacas y los elefantes, llegó también 
al Tibet. Entre los primeramente citados está el Yogasataka y el Astangahrdaya. En el siglo VIII, una gran obra de medicina hindú fue traducida al tibetano y en ella se encuentran partes textuales de los tratados médicos más importantes del Ayurveda.

En Japón se conservan, que se sepa desde el siglo VIII, medicamentos hindúes y sus nombres originales de la India en el Shoso-In, el Tesoro Imperial Japonés.

En Indochina e Indonesia el Ayurveda fue muy importante en tiempos antiguos.

En Arabia, la medicina hindú fue muy respetada. Mohamed Abu Bekr Ebn Zacarías (865-925), más conocido por al-Razi o Rhazés, famoso médico árabe, que viajó por Egipto, Siria y España y fue médico en el hospital de Bagdad, escribió diversas obras médicas que fueron traducidas al latín y muy respetadas en Europa, en las que mencionó e incorporó los conocimientos médicos hindúes. Una de sus obras, traducida al latín por Moisés Farachi hacia el siglo XIII, se convirtió en una obra clásica y otra, que trata de la viruela y el sarampión, fue publicada en una edición bilingüe latín-árabe por Channing, Londres, en 1966.

Mucho tiempo antes, el llamado "Hipócrates romano", Aulio Cornelio Celso, del primer siglo de nuestra era, escribió su De medicina libri VIII, publicado por primera vez en Florencia en 1478, pero reeditado muchas veces y que ejerció gran influencia en la medicina del Renacimiento. Pues bien, en su obra trata Celso de la litotomía (extracción de piedras de la vejiga) que se realizaba en la India mucho antes. Y el famoso Claudio Galeno (131-201 de nuestra era), que nació en Pérgamo y vivió en Roma, declara en sus obras que tomó de la India el ungüento para los ojos, un emplasto y otras medicinas.

$\mathrm{Y}$ es preciso subrayar que la hoy llamada cirugía reconstructiva, y antes cirugía plástica, llegó a occidente por medio de los médicos ingleses de la Compañia General de las Indias, que la descubrieron y aprendieron de los médicos ayurvédicos a fines del siglo XVIII.

Tal ha sido, en brevísima síntesis, la aportación del Ayurveda a la medicina en el mundo antiguo y en el moderno. 


\section{BIBLIOGRAFIA}

FILliozAT, J. La Doctrine Classique de la Médecine Indienne. Paris, Ecole Française d'Extrême-Orient, 1975.

MORA, J. M. La filosofía en la literatura sánscrita. México, UNAM, 1968.

PLATón, Diálogos. México, Editorial Porrúa, 1975.

RENOU, L. e FILLIOZAT, J. L'Inde Classique, Manuel des études indiennes. Paris, Ecole Française d'Extrême-Orient, 1953.

SUBBARAYAPPA, B. V. "India's contribution to the History of Science», en India's contribution to world thought and culture. Madras, Vivekananda Rock Memorial Committee, 1970.

Revisão técnica do Prof. Carlos Alberto da Fonseca (USP) Aceito para publicação em 01/02/1990 